Article

\title{
Fabrication and Testing of PVA/Chitosan Bilayer Films for Strawberry Packaging
}

\author{
Yaowen Liu ${ }^{1,2, *,+}$, Shuyao Wang ${ }^{1,+}$, Wenting Lan $^{1}$ and Wen Qin ${ }^{1}$ \\ 1 College of Food Science, Sichuan Agricultural University, Yaan 625014, China; shuyaow@126.com (S.W.); \\ 18227593253@163.com (W.L.); qinwen1967@yahoo.com.cn (W.Q.) \\ 2 School of Materials Science and Engineering, Southwest Jiaotong University, Chengdu 610031, China \\ * Correspondence: lyw@my.swjtu.edu.cn; Tel.: +86-835-8763-4068 \\ + These authors contributed equally to the work.
}

Received: 15 June 2017; Accepted: 13 July 2017; Published: 25 July 2017

\begin{abstract}
Strawberry packaging based on four different chitosan-poly(vinylalcohol) blend films with chitosan contents of $0 \mathrm{wt} \%, 20 \mathrm{wt} \%, 25 \mathrm{wt} \%$, and $30 \mathrm{wt} \%$ was tested. The samples were stored at $18 \pm 2{ }^{\circ} \mathrm{C}$ and $60 \% \pm 5 \%$ relative humidity for six days. Strawberry quality was evaluated during and after storage. Strawberries packaged using these films showed significant differences in weight loss and firmness, decay percentage, titratable acidity, total soluble solids, and ascorbic acid content when compared to non-packaged strawberries. The $25 \mathrm{wt} \%$ bilayer film showed the best performance in terms of delaying changes in strawberries. The findings suggest that these $25 \mathrm{wt} \%$ chitosan films can used to extend strawberry shelf lives while maintaining quality levels.
\end{abstract}

Keywords: bilayer films; strawberry; packaging

\section{Introduction}

The strawberry is among the most popular fruits worldwide, and is thus referred to as the "fruit queen". Strawberries possess high levels of antioxidant activity and vitamin E, vitamin C, $\beta$-carotene, and phenolic compounds such as anthocyanins, which benefit consumer health [1]. However, strawberries are perishable and have very short postharvest lives (around five days at $4{ }^{\circ} \mathrm{C}$ ) because of their susceptibility to mechanical damage, physiological deterioration, and lack protective rinds, which can exhibit symptoms of pathogens [2]. Previous research has reported that Botrytis cinerea determines strawberry shelf lives, so the inhibition of microbial growth can prolong sellable periods [3]. Some researchers have used fungicides to prevent postharvest rot by spraying them on the strawberries several times. However, the presence of residues limits the broad use of fungicides [4]. Controlling $\mathrm{CO}_{2}$ and $\mathrm{O}_{2}$ levels can also reduce the incidence of strawberry decay. Modified atmospheres with low $\mathrm{O}_{2}$ and high $\mathrm{CO}_{2}$ concentrations are very effective at inhibiting microbial growth and reducing the decay of fresh produce, including strawberries [5]. However, some experiments have shown that prolonged exposure of strawberries to high $\mathrm{CO}_{2}$ concentrations can cause the development of unwanted flavors [6]. To slow metabolic processes and reduce deterioration prior to transport, low temperatures are widely used to reduce spoilage and extend the lives of fresh fruits and vegetables. However, it is inconvenient and expensive to use transportable freezers or ice to control strawberry temperatures.

Biologically active packaging has become an effective method of controlling fungal decay, and several studies have investigated the potential of natural polymers for food protection. Most of these types of macromolecules can be processed into films or coated onto fruit surfaces. Owing to their high $\left(\mathrm{CO}_{2} / \mathrm{O}_{2}\right)$ permselectivities and ability to act as partial moisture barriers, these films can reduce fruit respiration and transpiration rates [7]. Biologically active packages include polysaccharides such as chitosan $(\mathrm{CH}) . \mathrm{CH}$ is a linear polysaccharide that consists of a low acetyl substituted form of chitin 
and a natural carbohydrate copolymer. $\mathrm{CH}$ offers several advantages such as biodegradability, broad availability, and non-toxicity [8]. $\mathrm{CH}$ also has good anti-fungal activity against several postharvest pathogens, particularly the grey mold that is one of the main causes of strawberry deterioration and postharvest decay [9]. Moreover, studies have demonstrated that $\mathrm{CH}$ can be mixed with other polymers to increase the shelf lives of fresh strawberries [10]. The use of liquid $\mathrm{CH}$ with strawberries would be effective, but would require high proportions, which would result in bad flavors, oily textures, and the potential for allergic reactions after consuming large amounts [11].

Unfortunately, pure $\mathrm{CH}$ films have high water vapor permeabilities and poor mechanical properties, and so cannot act as inert barriers between the product and the environment. In order to fulfill all necessary fruit packaging requirements, several methods of mixing $\mathrm{CH}$ with other polymers such as polylactic acid, poly(lactic-co-glycolic acid), polyethylene, etc. in composites have been developed. Poly(vinylalcohol) (PVA) is a hydroxyl-rich, semi-crystalline polymer. It can be processed using aqueous methods, and has several interesting physical properties that arise from the presence of hydroxyl groups and hydrogen bond formation. It is non-toxic, biocompatible and biodegradable, and offers good mechanical properties and chemical stability. Moreover, PVA/CH blends have good physical and antibacterial properties because of specific intermolecular interactions between PVA and $\mathrm{CH}$. PVA/CH blend films represent a better choice for strawberry packaging than coating $\mathrm{CH}$ on the fruit surface or refrigeration. These blends are especially appropriate for transportation due to their good mechanical and oxygen barrier properties [12].

In order to prolong the shelf life of strawberries and reduce the hazard of ingesting chemical reagents, edible coating materials have been widely studied. PVA/CH blend films with various $\mathrm{CH}$ contents on fresh strawberries were determined in this study. The films were characterized based on scanning electron microscopy (SEM), mechanical tests, oxygen permeability (OP) and water vapor permeability (WVP). Non-packaged strawberries and strawberries packaged with four different films were compared and analyzed in terms of color, weight loss, decay percentage ( $\%$ decay), firmness, soluble solid content (SSC), titratable acidity (TA), and sensory characteristics.

\section{Results and Discussion}

\subsection{SEM Analysis}

The weight ratios of PVA:CH of 80:20, 75:25, and 70:30 were denoted as PVA/CH-2, PVA/CH-2.5, and PVA/CH-3, respectively [13]. The morphologies of the PVA film, PVA/CH-2, PVA/CH-2.5, and PVA/CH-3 are seen clearly in the SEM images (Figure 1). PVA film presents good structural integrity, smoothness, flatness, and crack-free states. $\mathrm{CH}$ shows even distributions in PVA/CH-2, and PVA/CH-2.5 films, demonstrating the high compatibility of the two polymers and a compact structure lacking phase separation [14]. No air bubbles, pores, cracks, or droplets are observed, further confirming the high compatibility of the two polymers, similar to that observed by Tripathi et al. [15]. However, when the $\mathrm{CH}$ content is increased, it appears visibly as rough areas. The rough areas of the PVA/CH-3 show scaly structures. The roughness is because the $\mathrm{CH}$ molecules disrupt the compact structure of the PVA matrix. The incorporation of $\mathrm{CH}$ minimizes the free volume of the matrix, condensing the microstructure of the film [16]. These structural properties of the dried $\mathrm{CH}$ matrices may offer a larger surface area, and therefore, better matrix-solvent interactions, allowing for faster solvent uptake. This leads to dissociation, with the most obvious result of scaly structures [15]. 

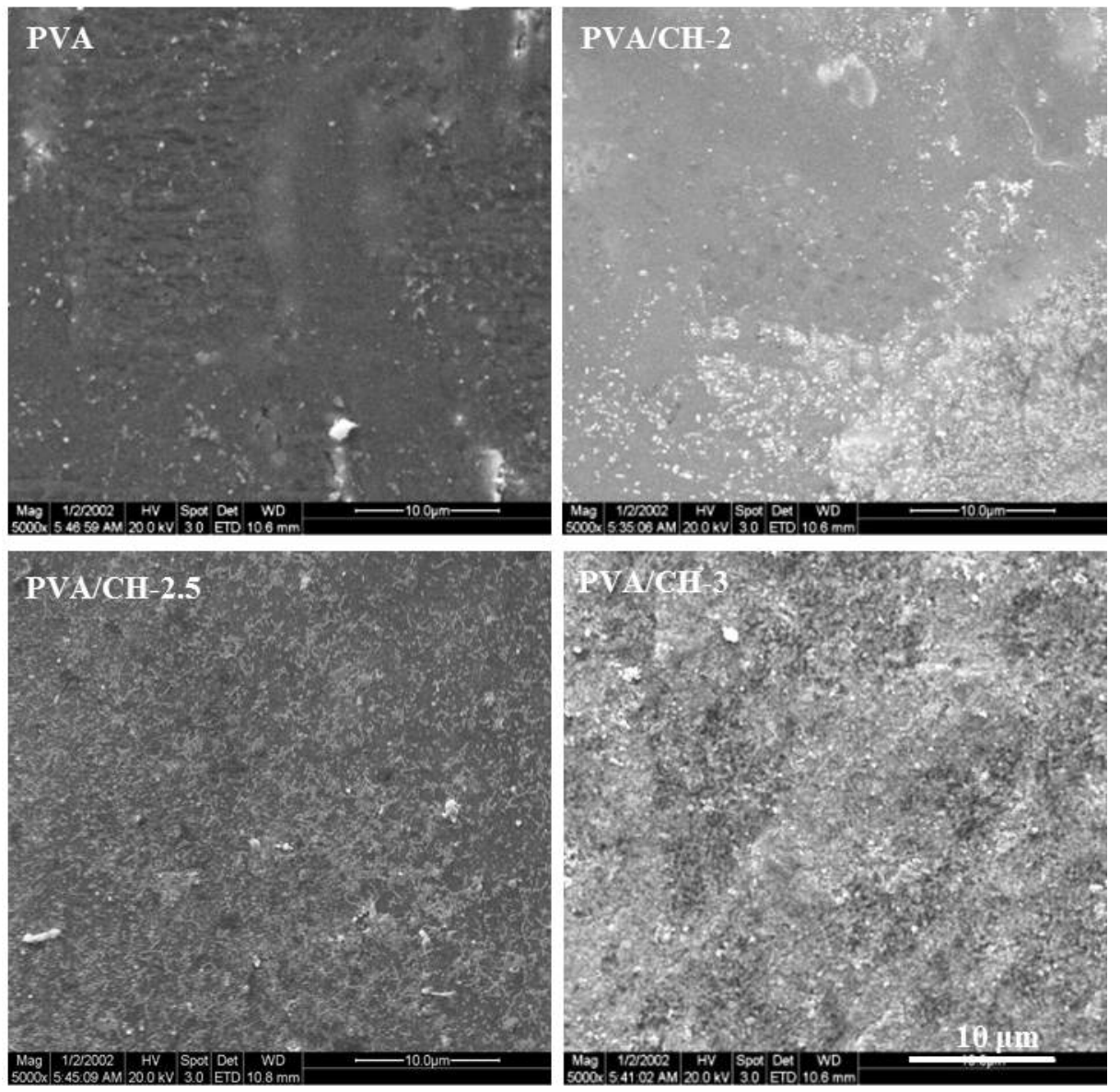

Figure 1. Scanning electron microscopy (SEM) morphologies of pure Poly(vinylalcohol) (PVA) film and different PVA/CH films.

\subsection{FT-IR Analysis}

Figure 2 presents the characteristic attenuated total reflectance-Fourier transform infrared (ATR-FTIR) spectra corresponding to $\mathrm{CH}, \mathrm{PVA}$, and PVA/CH-2.5. For PVA film, the bands at approximately $3455 \mathrm{~cm}^{-1}$ and $1630 \mathrm{~cm}^{-1}$ are assigned to the stretching and bending vibrations of the hydroxyl group, respectively [17]. The band corresponding to asymmetric stretching vibrations of the methylene group occurs at approximately $2933 \mathrm{~cm}^{-1}$. The band at approximately $1096 \mathrm{~cm}^{-1}$ corresponds to $\mathrm{C}-\mathrm{O}$ stretching in the acetyl groups present on the PVA backbone [18]. Notably, the bands of $\mathrm{CH}$ are assigned to the saccharide structure at $1166 \mathrm{~cm}^{-1}, 1077 \mathrm{~cm}^{-1}$, and $1018 \mathrm{~cm}^{-1}$. The strong amino characteristic bands at $3430 \mathrm{~cm}^{-1}, 1660 \mathrm{~cm}^{-1}$, and $1290 \mathrm{~cm}^{-1}$ are assigned to hydroxyl stretching, amide I, and amide II, respectively [19]. The spectra of PVA/CH-2.5 indicates clear increases in the intensity of the band at $3380 \mathrm{~cm}^{-1}$, attributed to hydroxyl group stretching vibrations of PVA, with a secondary amide group of $\mathrm{CH}$. The band at approximately $1077 \mathrm{~cm}^{-1}$ indicates the presence of a hydroxyl group with polymeric association and a secondary amide. The band at $1450 \mathrm{~cm}^{-1}$, appearing for weight fractions of $25 \% \mathrm{CH}$, is assigned to $\mathrm{C}=\mathrm{N}$ pyridine ring vibrations. This confirmed the complexation between the PVA and $\mathrm{CH}$ [19]. For all PVA/CH films, the characteristic bands are similar to those of PVA; strong amorphous carbonyl stretching vibrations of PVA remain constant in all films. The peak intensity increases with increased $\mathrm{CH}$ contents. The characteristic shape of the $\mathrm{CH}$ spectrum is changed, and the peak shifts to a lower frequency range because of hydrogen bonding between the hydroxyl groups of PVA and hydroxyl, or amine groups of $\mathrm{CH}$ in the blended films [20]. Kim et al. also reported that the crystallization-sensitive band of PVA at $1140 \mathrm{~cm}^{-1}$ was observed with a similar intensity without significant changes in frequency for PVA and blended films [21]. 


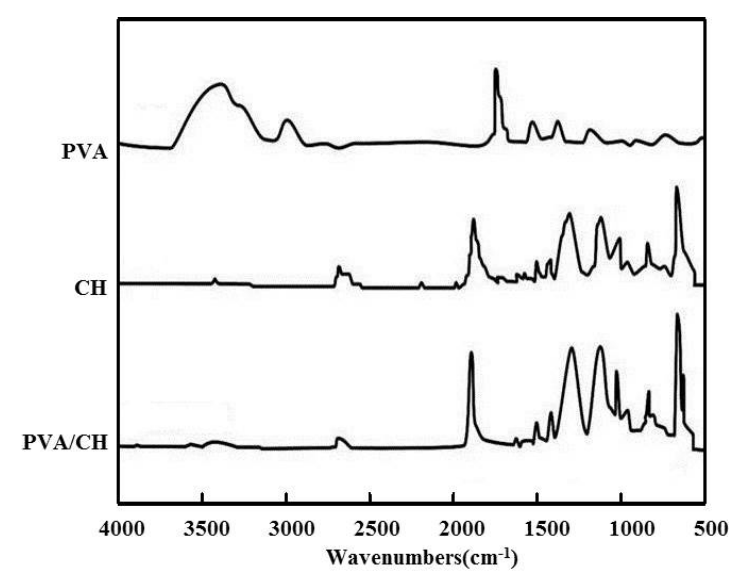

Figure 2. Attenuated total reflectance-Fourier transform infrared (ATR-FTIR) spectra of PVA, CH, and PVA/CH-2.5 films.

\subsection{Mechanical Properties}

Table 1 shows the mechanical properties of pure PVA film and PVA with different $\mathrm{CH}$ weight ratios. The ultimate stress of PVA film is $25.08 \pm 4.32 \mathrm{MPa}$, and the specific deformation is $72.97 \% \pm 7.26 \%$. When the concentration of $\mathrm{CH}$ in the PVA/CH films is increased, the ultimate stress of the films is also increased, while the elongation at break of the films is decreased. Compare to the pure PVA film, the stress of PVA/CH film increases from $29.76 \pm 4.81 \mathrm{MPa}$ to $35.39 \pm 5.35 \mathrm{MPa}$, while the strain decreases from $77.13 \% \pm 7.94 \%$ to $72.91 \% \pm 8.17 \%$. Bispo et al. proposed that films formed from polymer blends present intermediate values of maximum stress compared with those of films comprising the pure components [22]. Therefore, the mechanical properties of the PVA/CH films may suggest that the PVA polymer has greater influence on the tensile stress and maximum specific deformation. The increases in $\mathrm{CH}$ content cause change in stress and strain, due to the thermodynamic immiscibility and inherent incompatibility between thermoplastic polymers and $\mathrm{CH}$ [23]; the $\mathrm{CH}$ also disrupts the intramolecular hydrogen bonding of the PVA molecules [23]. Moreover, as the $\mathrm{CH}$ addition is increased, this changed the intermolecular hydrogen bonds formed between the amine and hydroxyl groups of $\mathrm{CH}$ [24]. However, PVA/CH-2.5 shows the best mechanical properties (Young's modulus $63.57 \pm 6.98 \mathrm{MPa}$; those results proved that blend miscibility of the two polymers as a function of molecular interactions between PVA and $\mathrm{CH}$ [25].

Table 1. Mechanical properties of pure PVA film and PVA/CH with different $\mathrm{CH}$ weight ratios.

\begin{tabular}{ccccc}
\hline Samples & Thickness $(\mu \mathrm{m})$ & Stress $(\mathrm{MPa})$ & Strain $(\%)$ & Young's Modulus $^{(M P a)}$ \\
\hline PVA & $373.1 \pm 12.8^{\mathrm{a}}$ & $25.08 \pm 4.32^{\mathrm{a}}$ & $82.97 \pm 7.26^{\mathrm{a}}$ & $56.11 \pm 5.84^{\mathrm{a}}$ \\
PVA/CH-2 & $396.4 \pm 13.4^{\mathrm{a}}$ & $29.76 \pm 4.81^{\mathrm{a}}$ & $77.13 \pm 7.94^{\mathrm{b}}$ & $59.53 \pm 6.42^{\mathrm{a}}$ \\
PVA/CH-2.5 & $418.6 \pm 14.7^{\mathrm{b}}$ & $35.39 \pm 5.35^{\mathrm{b}}$ & $75.33 \pm 8.44^{\mathrm{b}}$ & $63.57 \pm 6.98^{\mathrm{b}}$ \\
PVA/CH-3 & $433.9 \pm 15.1^{\mathrm{b}}$ & $31.44 \pm 5.12^{\mathrm{a}}$ & $72.91 \pm 8.17^{\mathrm{b}}$ & $58.45 \pm 6.35^{\mathrm{a}}$ \\
\hline
\end{tabular}

Notes: Values with the same letter are not statistically different, according to Duncan's Multiple Range Test at $p<0.05 ; \mathrm{a}, \mathrm{b}$, means with the same letter in the same column are not significant different $(p>0.05)$.

\subsection{Oxygen Permeability and Water Vapor Permeability}

The OPs of packaging materials are of considerable importance in food preservation. Low OPs indicate excellent oxygen barrier properties. Table 2 shows the OP and WVP values for all films. The OP of the pure PVA film is $0.12 \pm 0.04 \mathrm{~cm}^{2} \mathrm{~m}^{-2} \mathrm{~atm}^{-1}$ day $^{-1} \mathrm{MPa}$. The addition of $\mathrm{CH}$ reduces the abilities of the blend films to act as oxygen barriers. The OPs of PVA/CH-2 and PVA/CH-2.5 increase slightly, from $0.15 \pm 0.07$ to $0.16 \pm 0.08 \mathrm{~cm}^{2} \mathrm{~m}^{-2} \mathrm{~atm}^{-1}$ day ${ }^{-1} \mathrm{MPa}$. This can be attributed to the lower crystallinities of the blended films with low $\mathrm{CH}$ concentrations [26]. The OPs increase 
rapidly with the $\mathrm{CH}$ content when the latter is over $30 \mathrm{wt} \%$, resulting in blend films with poorer oxygen barrier properties.

Table 2. Oxygen permeability and water vapor permeation of different films.

\begin{tabular}{ccc}
\hline Samples & Oxygen Permeability $\left(\mathbf{c m}^{\mathbf{2}} \mathbf{~ m}^{\mathbf{2}} \mathbf{d a y}^{\mathbf{- 1}} \mathbf{M P a}{ }^{-\mathbf{1}}\right)$ & Water Vapor Permeation $\left(\mathrm{g} \mathrm{cm}^{\mathbf{- 1}} \mathbf{~ s}^{\mathbf{- 1}} \mathbf{P a}^{-\mathbf{1}}\right)$ \\
\hline PVA & $0.12 \pm 0.04^{\mathrm{b}}$ & $10.11 \pm 2.14^{\mathrm{b}}$ \\
PVA/CS-2 & $0.15 \pm 0.07^{\mathrm{b}}$ & $12.43 \pm 3.72^{\mathrm{b}}$ \\
PVA/CS-2.5 & $0.16 \pm 0.08^{\mathrm{b}}$ & $14.93 \pm 4.09^{\mathrm{b}}$ \\
PVA/CS-3 & $0.39 \pm 0.11^{\mathrm{a}}$ & $22.99 \pm 5.57^{\mathrm{a}}$ \\
\hline
\end{tabular}

Notes: Values with the same letter are not statistically different, according to Duncan's Multiple Range Test at $p<0.05 ;{ }^{a}, \mathrm{~b}$, means with the same letter in the same column are not significant different $(p>0.05)$.

The WVPs of PVA/CH-2 and PVA/CH-2.5 films are $12.43 \pm 3.72$, and $14.93 \pm 4.09 \mathrm{~g} \mathrm{~cm}^{-1} \mathrm{~s}^{-1} \mathrm{~Pa}^{-1}$, respectively. This demonstrates that the WVPs of the composite films are higher than that of the pure PVA film $\left(10.11 \pm 2.14 \mathrm{~g} \mathrm{~cm}^{-1} \mathrm{~s}^{-1} \mathrm{~Pa}^{-1}\right)$; however, the differences are not significant. PVA/CH-3 film exhibits significantly higher WVPs $(p<0.05)$ than PVA. Those results indicated that the interaction between PVA and $\mathrm{CH}$ can increase the water vapor barrier properties. Furthermore, increasing the $\mathrm{CH}$ content clearly increases the WVPs of the films. The hydrophilic nature of $\mathrm{CH}$ favors the transport of water molecules through the film [27], and composite films with higher $\mathrm{CH}$ contents exhibit lower crystallinities [28].

\section{5. $p H$ Values}

Table 3 compared the $\mathrm{pH}$ values of packaged and unpackaged strawberries. The $\mathrm{pH}$ values of unpackaged strawberries increased significantly with the increase of storage time. The $\mathrm{pH}$ values of unpackaged strawberries reached to $3.99 \pm 0.29$ after six days. Han et al. demonstrated that the $\mathrm{pH}$ values of fruit are related to the fruit senescence [29]. A possible explanation for this might be the utilization of organic acids of fruit during respiration [30]. The $\mathrm{pH}$ difference between day 2 and day 4 was not statistically significant for all packaged groups. Martinez-Ferrer et al. considered that might be the low conversion rate of organic acids during respiration [30]. The $\mathrm{pH}$ values of strawberries packaged with PVA/CH-2, PVA/CH-2.5 and PVA/CH-3 were significantly different than the $\mathrm{pH}$ values of strawberries packaged with the PVA sample at day 6 . The findings of the current study are consistent with those of Cong et al., who found that $\mathrm{CH}$ coating containing natamycin slowed the changes in $\mathrm{pH}$ values of Hami melons [31]. At six days, the $\mathrm{pH}$ values of fruits packaged with PVA/CH-2.5 was $3.65 \pm 0.16$, and the change was minimum ( $3.41 \pm 0.08$ for one day). A possible explanation for this might be that relatively small changes of $\mathrm{O}_{2}$ and $\mathrm{CO}_{2}$ levels resulted in slight changes of the $\mathrm{pH}$ values for strawberries [32].

Table 3. $\mathrm{pH}$ analysis of strawberries treated with different films during storage.

\begin{tabular}{cccccccc}
\hline \multirow{2}{*}{ Treatments } & \multicolumn{7}{c}{$\mathbf{p H}$} \\
\cline { 2 - 8 } & 0 Day & 1 Day & 2 Days & 3 Days & 4 Days & 5 Days & 6 Days \\
\hline Unpackaged & $3.41 \pm 0.08^{\mathrm{b}}$ & $3.53 \pm 0.12^{\mathrm{b}}$ & $3.64 \pm 0.16^{\mathrm{b}}$ & $3.70 \pm 0.18^{\mathrm{b}}$ & $3.76 \pm 0.20^{\mathrm{b}}$ & $3.88 \pm 0.24^{\mathrm{a}}$ & $3.99 \pm 0.29^{\mathrm{a}}$ \\
PVA & $3.41 \pm 0.08^{\mathrm{b}}$ & $3.49 \pm 0.11^{\mathrm{b}}$ & $3.57 \pm 0.14^{\mathrm{b}}$ & $3.64 \pm 0.16^{\mathrm{b}}$ & $3.71 \pm 0.18^{\mathrm{b}}$ & $3.77 \pm 0.20^{\mathrm{a}}$ & $3.83 \pm 0.23^{\mathrm{a}}$ \\
PVA/CH-2 & $3.41 \pm 0.08^{\mathrm{b}}$ & $3.47 \pm 0.10^{\mathrm{b}}$ & $3.53 \pm 0.13^{\mathrm{b}}$ & $3.57 \pm 0.14^{\mathrm{b}}$ & $3.62 \pm 0.16^{\mathrm{b}}$ & $3.69 \pm 0.18^{\mathrm{b}}$ & $3.76 \pm 0.20^{\mathrm{b}}$ \\
PVA/CH-2.5 & $3.41 \pm 0.08^{\mathrm{b}}$ & $3.46 \pm 0.09^{\mathrm{b}}$ & $3.51 \pm 0.12^{\mathrm{b}}$ & $3.55 \pm 0.14^{\mathrm{b}}$ & $3.59 \pm 0.05^{\mathrm{b}}$ & $3.61 \pm 0.16^{\mathrm{b}}$ & $3.65 \pm 0.16^{\mathrm{b}}$ \\
PVA/CH-3 & $3.41 \pm 0.08^{\mathrm{b}}$ & $3.46 \pm 0.09^{\mathrm{b}}$ & $3.51 \pm 0.12^{\mathrm{b}}$ & $3.57 \pm 0.15^{\mathrm{b}}$ & $3.61 \pm 0.16^{\mathrm{b}}$ & $3.68 \pm 0.18^{\mathrm{b}}$ & $3.74 \pm 0.20^{\mathrm{b}}$ \\
\hline
\end{tabular}

Notes: Values with the same letter are not statistically different, according to Duncan's Multiple Range Test at $p<0.05 ; \mathrm{a}, \mathrm{b}$, means with the same letter in the same column are not significant different $(p>0.05)$.

\subsection{Weight Loss}

Owing to respiration and transpiration, strawberries are highly susceptible to the rapid loss of water. In our studies, weight loss was tracked over the storage period of six days. Figure 3a shows that 
all strawberries experience progressive weight loss during the storage period. The packaged samples experience significantly less weight loss than non-packaged samples after two days $(p<0.05)$. This is because the major cause of weight loss among non-packaged samples is the migration of water from the fruit to the environment [33], and the packaging materials serve as semipermeable barriers that block oxygen, carbon dioxide, and moisture. This reduces respiration, water loss, and oxidation [34]. Since PVA has the lowest water vapor permeability, strawberries packaged with it exhibit the lowest weight loss. PVA/CH-2.5 exhibits the lowest weight loss among the PVA/CH bilayer films. This is because PVA/CH-2.5 has higher oxygen permeability, and the hydrophilic $\mathrm{CH}$ interacts with water molecules to increase the transport of water vapor. Hence, the packaging of strawberries in bilayer films is clearly effective in providing a physical barrier to moisture loss, and therefore in retarding respiration and fruit shriveling [35].
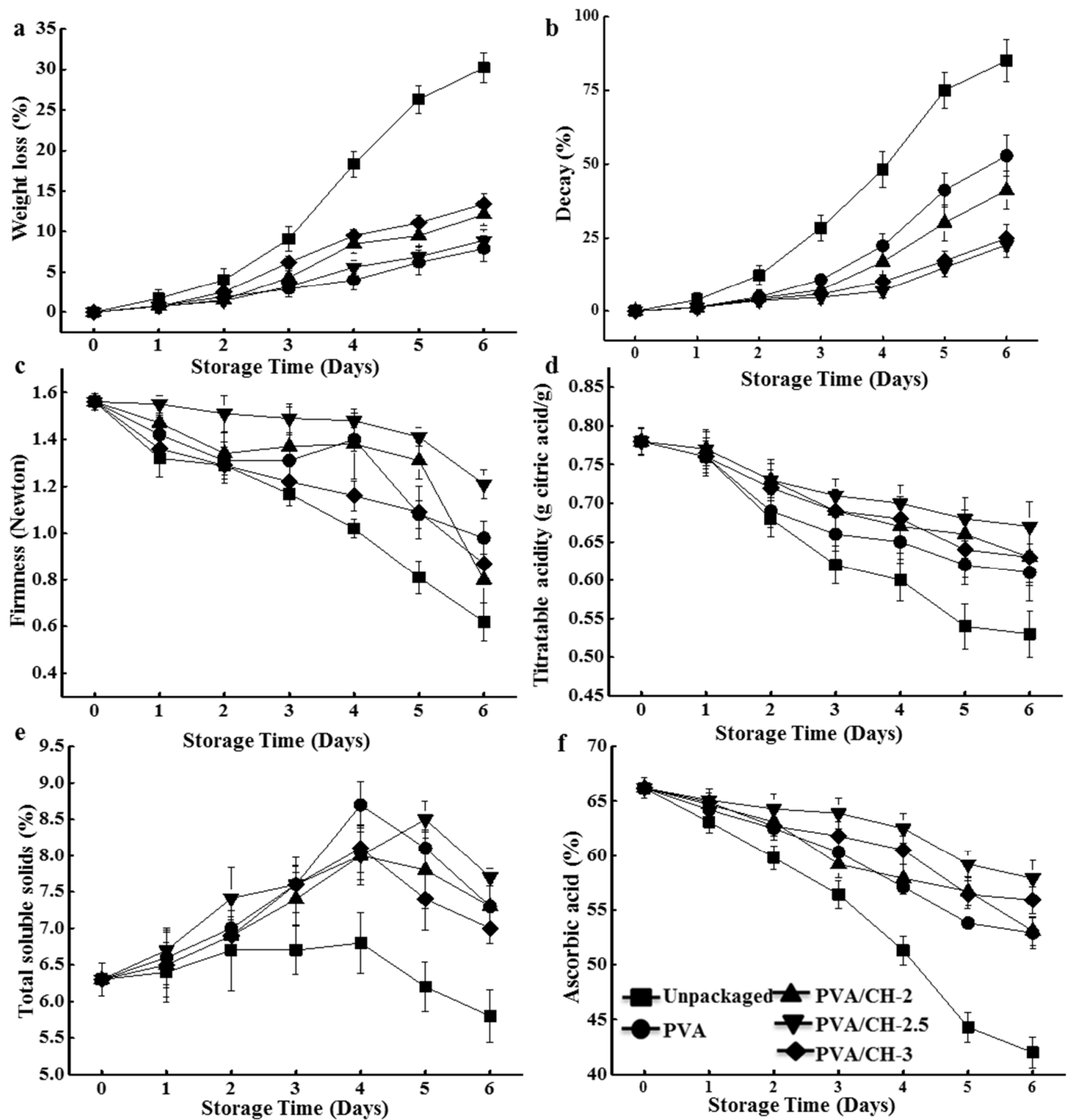

Figure 3. Effect of unpackaged PVA and different PVA/CH films on the (a) weight loss, (b) decay, (c) firmness, (d) titratable acid, (e) total soluble solids and (f) ascorbic acid quality parameters of strawberries during storage times. 


\subsection{Decay Percentage}

Strawberries are highly perishable fruits with high postharvest physiological activities that limit their shelf lives. Generally, the infected areas increase gradually with storage time, as shown in Figure $3 \mathrm{~b}$. The decay percentages of the packaged strawberries range from $22.7 \% \pm 3.2 \%$ to $52.9 \% \pm 5.7 \%$, but the non-packaged strawberries experience a decay of $85.1 \% \pm 7.4 \%$ after 6 days. The packaging significantly reduces strawberry decay during the six days test $(p<0.05)$. PVA/CH films and pure PVA film can decrease the rate at which the fruit rots as well. Some studies have indicated that $\mathrm{CH}$ appears to have multiple functions, as it interferes directly with fungal growth and activates several biological processes in plant tissues [36]. PVA/CH-2.5 reduces the degree of decay better than other packaging materials throughout the storage period. This may be because of its WVP and OP, which may affect the growth environment for bacteria.

\subsection{Firmness}

Loss of texture is one of the main factors that limits quality and the postharvest shelf lives of fruit and vegetables. Therefore, texture is an important strawberry quality parameter. During ripening, strawberries soften considerably due to degradation of the middle lamella of the cell wall. Cortical parenchyma cells, cell wall strengths, cell-to-cell contact [37], and cellular turgor can also influence firmness [38]. The changes in strawberry firmness are shown in Figure 3c. The firmness of all strawberries was significantly lower among the non-packaged samples than among the packaged fruit $(p<0.05)$. This leads to increased water loss and fungal infections among strawberries that lack packaging protection, which leads to more pronounced tissue senescence and broken cell walls [39]. After four days, the firmness curve exhibits a turning point. The firmness of all packaged strawberries begins to decrease significantly due to senescence, which softens the fruit via pectin hydrolysis, and depolymerization degradation of the cell wall [40]. After six days, the loss of firmness is approximately $48 \%$ among non-packaged fruit. The losses are 31.5\% $\pm 9.7 \%, 16.2 \% \pm 4.7 \%, 10.4 \% \pm 2.4 \%$, and $20.6 \% \pm 5.1 \%$ in PVA, PVA/CH-2, PVA/CH-2.5 and PVA/CH-3 packaged fruit samples, respectively. The PVA/CH-2.5 samples do not experience significant surface softening when compared to the fresh strawberries, and the film is effective with regard to firmness retention. It also has been reported that chitosan coatings and other biopolymers are selective $\mathrm{O}_{2}$ and $\mathrm{CO}_{2}$ barriers, and thus can modify the internal atmosphere and slow the respiration rates of fresh fruits and vegetables [41].

\subsection{Titrable Acidity (TA)}

Organic acids are among the most important components of the flavor of a strawberry. Changes in acidity are significantly affected by the rate of metabolism, especially respiration. Respiration consumes organic acid, and therefore acidity declines during storage. This is also the main cause of fruit senescence [10]. The effect of packaging on the TA of strawberries is shown in Figure 3d. At the end of the storage period, the TA of non-packaged strawberries decreases significantly faster $(p<0.05)$ than packaged samples. This is because the packaging can modify the internal atmosphere around the strawberries, and may therefore delay the utilization of organic acids. The decrease in the TA of the PVA-packaged fruit is less (23.4\%) than that of the unpackaged fruit $(36.5 \%)$, but more than that of fruit protected by PVA/CH films (from 17.6\% to 19.8\%). This suggests that bilayer films are better than pure PVA materials at delaying decreases in TA during storage. The PVA/CH-2.5 bilayer film is the most effective at maintaining higher TA levels after six days.

\subsection{Total Soluble Solids (TSS)}

Total soluble solids (TSS) is an important parameter that affects fruit quality and consumer acceptability. Changes in the TSSs of strawberry samples with storage time are shown in Figure 3e. The TSS increases significantly during four days of storage. Starting on the fifth day, the TSS begins to decrease rapidly in PVA-packaged samples (from 8.7\% to 7.3\%) due to hydrolysis. Experiments also 
show that adding $\mathrm{CH}$ to the coating formulation helps to maintain higher TSS accumulation at the end of the storage period. After six days, the PVA/CH bilayer film slows the conversion that reduces sugar levels in the strawberries. The PVA/CH-2.5 sample retains the highest TSS in the current work, which can be explained by the considerable loss of water experienced by strawberries during storage at room temperature. The PVA/CH-2.5 bilayer film offers the most suitable environment for strawberry preservation, as previously noted with regard to weight loss.

\subsection{Ascorbic Acid}

Obviously, the ascorbic acid content gradually declines with postharvest elongation in both packaged and non-packaged fruits (Figure 3f). All packaging materials inhibited ascorbic acid loss in packaged fruit. With the PVA/CH-2.5 film, the ascorbic acid content decreased from $66.2 \pm 4.8 \mathrm{mg} / 100 \mathrm{~g}$ (one day) to $57.9 \pm 3.6 \mathrm{mg} / 100 \mathrm{~g}$ (six days), while the unpackaged samples showed significantly $(p<0.05)$ lower amounts of ascorbic acid $(42.4 \pm 2.9 \mathrm{mg} / 100 \mathrm{~g}$, six days $)$. Some studies have also shown that the incorporation of $\mathrm{CH}$ can slow the deteriorative oxidation of ascorbic acid in fruit [10]. During storage, strawberry decay and the low $\mathrm{CH}$ content increase ascorbic acid degradation.

\subsection{Sensory}

Sensory acceptance scores, including those for appearance, color, odor, flavor, texture, and overall acceptability were measured after six days and are shown in Figure 4. The appearance acceptability scores of the control strawberries are significantly different from those of the packaged strawberries after two days. The control and PVA-packaged strawberries have unacceptable scores after four days of storage, while the PVA/CH films maintain acceptable scores (greater than five) until five days. The color acceptability scores of the packaged strawberries do not change significantly until after three days of storage. After three days, the color acceptability of samples other than PVA/CH-2.5 decrease significantly. The odor acceptability scores of the control strawberries fail consumer acceptance after four days. The odor acceptability scores of the PVA/CH-2 and PVA/CH-3 samples are almost equal, with the former having the highest scores. The control has the lowest odor acceptability score after six days. The flavor acceptability scores of all strawberries decrease significantly during the six days. The scores of PVA-packaged strawberries are greater than those of the control strawberries, and are the highest among all of the samples after two days. Both control and PVA-packaged strawberries are unacceptable after five days. Although the flavor scores of PVA/CH film-packaged strawberries decrease during the 6 days of testing, they remain acceptable. The overall acceptance scores of the control strawberries decrease during storage. The PVA and PVA/CH-2-packaged strawberries are not acceptable after five days. However, the PVA/CH-2.5 and PVA/CH-3 samples are still acceptable at the end of the storage period. This finding agrees with those of Sangsuwan et al., who reported that $\mathrm{CH}$ beads loaded with lavender essential oil can extend the mold-free storage lives of strawberries stored at $7{ }^{\circ} \mathrm{C}$ from two days (control) to eight days with acceptable overall sensory scores [43].

The result of sensory evaluation was similar to the appearance changes of strawberries. As shown in Figure 5, both packed and unpacked strawberries have begun to decay after four days except the group packed with PVA-CH-2.5 film. The decay of the strawberries could have been prevented by PVA-CH-2.5 film until the 6 th day. The mold and yeast counts during the 6 days storage also proved the similar conclusion.

As shown in Figure 6, the strawberries packaged with PVA/CH films presented a significantly lower amount of mold and yeast growth than the uncoated strawberries $(p<0.05)$. Moreover, the mold and yeast reduction was more evident in the strawberries that were packaged with high concentration $\mathrm{CH}$ due to the antimicrobial capacity of $\mathrm{CH}$, especially against the fungi and yeast spoilage of strawberries [44]. $\mathrm{CH}$ potentially causes severe cellular damage in mold and yeast by altering the synthesis of fungal enzymes [45], inducing morphological changes, and causing structural alterations and molecular disorganization in fungal cells [46]. Similar results were observed by 
Valenzuela et al. [44]. The results achieved here also indicated that PVA/CH-2.5 film can not only maintain the nutritive and organoleptic properties of strawberries, it could also reduce the amount of mold and yeast during storage times. The high effectiveness of PVA/CH-2.5 is due to the ionic and hydrophilic interaction between PVA and $\mathrm{CH}$, which increased the availability of the amino groups of the $\mathrm{CH}$ to the antimicrobial properties [44].
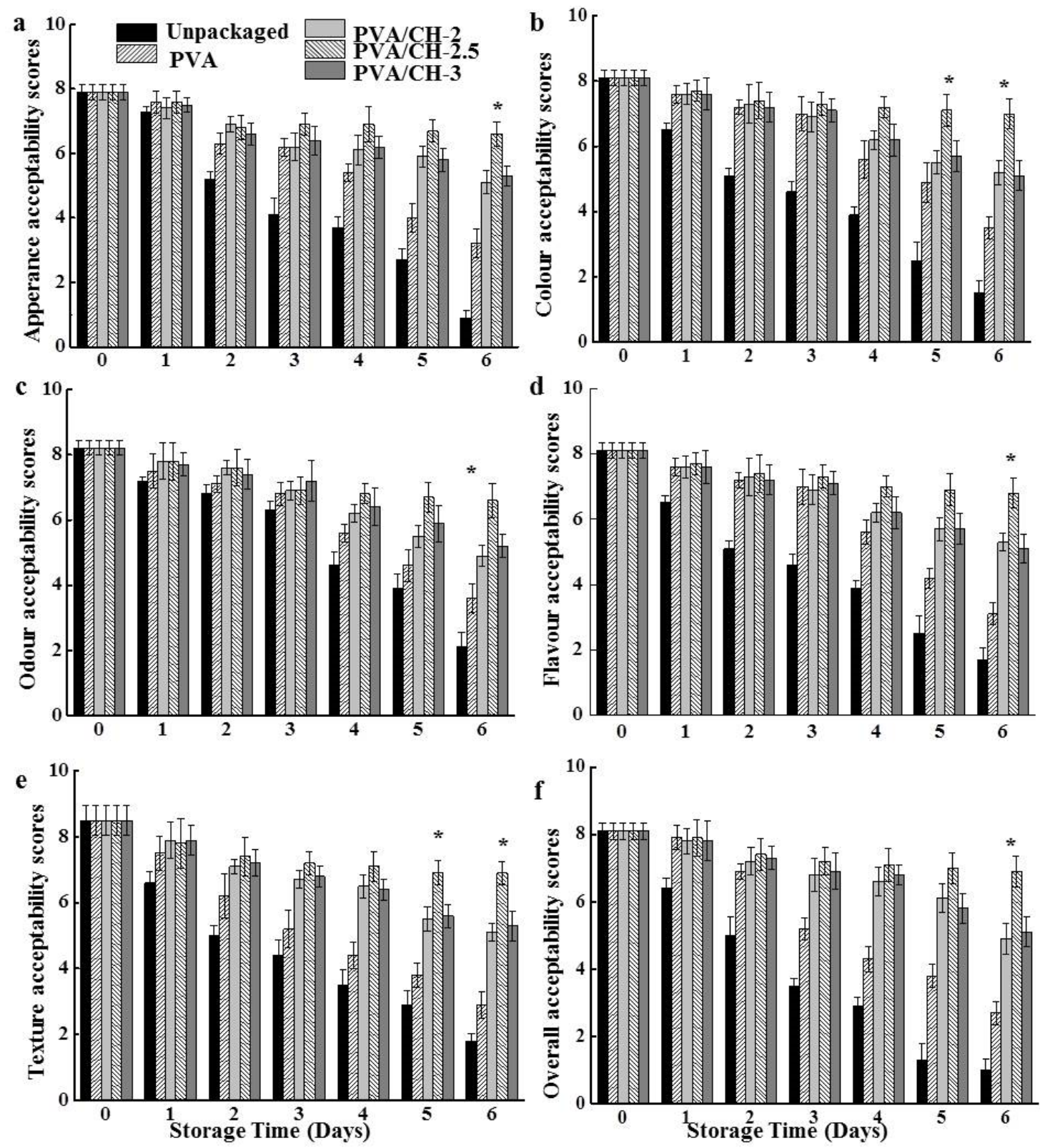

Figure 4. The sensory scores of (a) appearance acceptability; (b) color acceptability; (c) odor acceptability; (d) flavor acceptability; (e) texture acceptability and (f) overall acceptability of strawberries during storage times. 


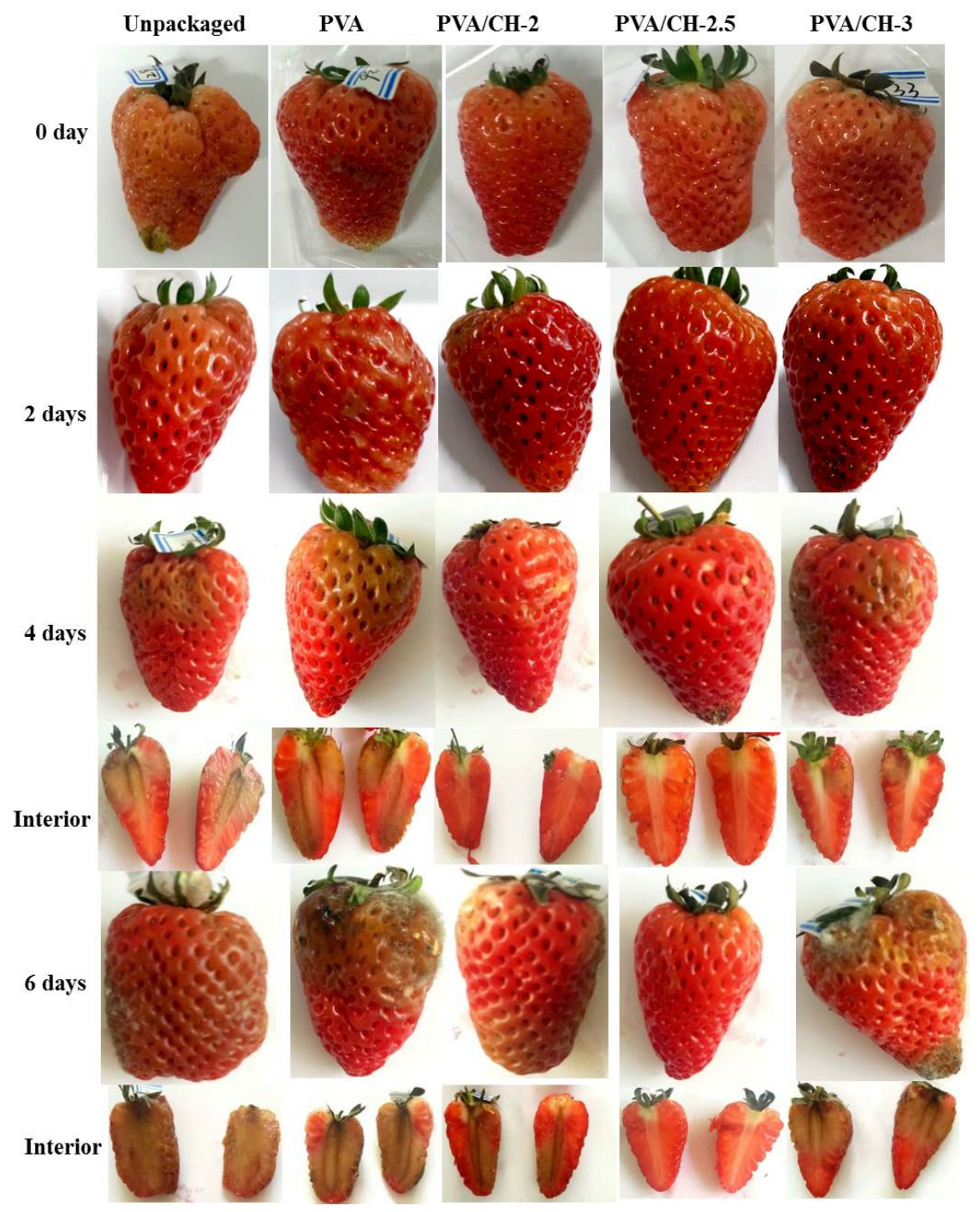

Figure 5. Digital images of the appearance and inner changes of strawberries during storage times.

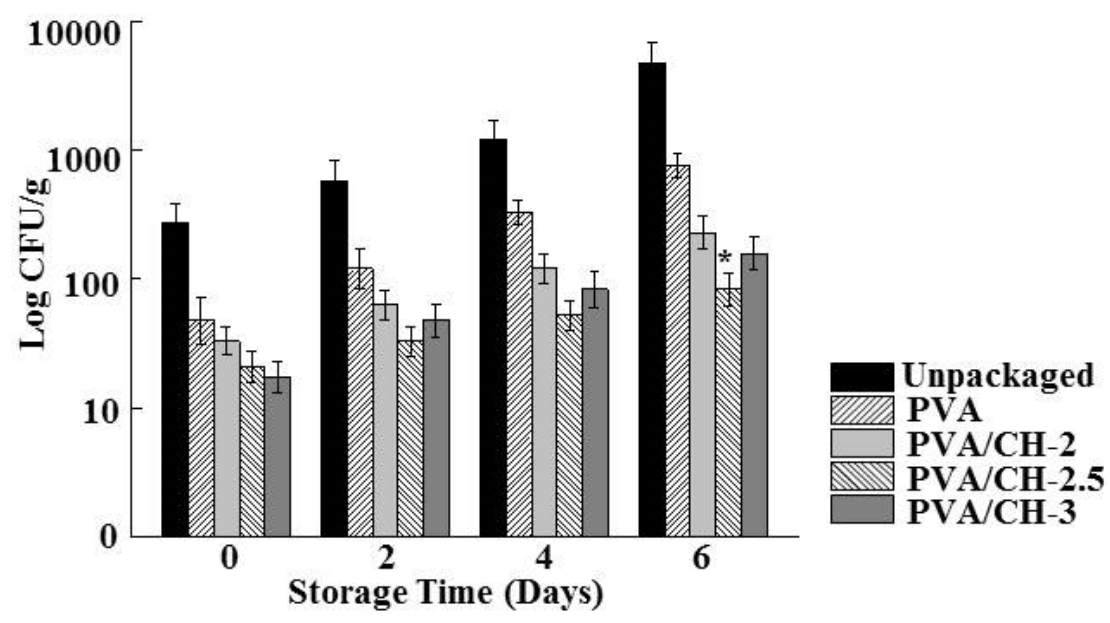

Figure 6. Evolution of mold and yeast counts of unpackaged and packaged strawberries with different $\mathrm{PVA} / \mathrm{CH}$ films during storage times. 


\section{Materials and Methods}

\subsection{Materials}

$\mathrm{CH}$ (food grade, 90\% degree of deacetylation, molecular mass of 165,000 Da, low viscosity) was obtained from Shangdong Aokang Biological Technology (Jinan, Shangdong, China). PVA with molecular weight of 124,000-186,000 was purchased from Sigma Aldrich (98\%, St. Louis, MO, USA). Acetic acid (glacial 100\%, water solution) was obtained from Guoling Instrument Inc. (Dongguan, China) All other chemical reagents used were of analytical grade and obtained from Chengdu Kelong Reagent Co. (Chengdu, China), unless otherwise indicated. Strawberries were harvested from an orchard in Shuangliu, Sichuan. The selected fruit was of uniform size and color and free of physical damage and fungal infection. They were washed with $1 \%$ sodium hypochlorite for $1 \mathrm{~min}$, then rinsed with distilled water and allowed to dry. Packaging experiments were carried out on the same day.

\subsection{PVA/CH Film Preparation}

PVA was dissolved in boiling water at $100{ }^{\circ} \mathrm{C}$ and stirred for $8 \mathrm{~h}$ to produce a clear, $10 \mathrm{wt} \%$ solution. It was degassed in a vacuum desiccator and poured into a Teflon pan $(20 \mathrm{~cm} \times 20 \mathrm{~cm})$. The solution was dried in an oven at $50{ }^{\circ} \mathrm{C}$ for four days to ensure the removal of residual solvents, and the film was peeled from the pan and kept in a vacuum oven until use. To produce a completely homogenized $\mathrm{CH}$ solution, various $\mathrm{CH}$ mass ratios were dissolved in $0.8 \%$ acetic acid and stirred overnight. Briefly, a CH solution in acetic acid/water/ethanol was loaded into a syringe equipped with a metal capillary. A rotating metal plate collector was placed approximately $5 \mathrm{~cm}$ from the capillary tip. The solution was extruded from the needle tip at a constant flow rate of $10 \mu \mathrm{L} / \mathrm{min}$ using a precision pump (Zhejiang University Medical Instrument Company, Hangzhou, China). The applied voltage was set to approximately $15 \mathrm{kV}$ using a high-voltage statitron (Tianjing High Voltage Power Supply Company, Tianjing, China). Low-humidity conditions were created by using a dehumidifier during the electrospray process. After $\mathrm{CH}$ deposited on both surfaces, the films were dried, first in a vacuum at $50{ }^{\circ} \mathrm{C}$ for $24 \mathrm{~h}$ and then at $18 \pm 2{ }^{\circ} \mathrm{C}$.

\subsection{Film Characterization}

The pure PVA, PVA/CH-2, PVA/CH-2.5, and PVA/CH-3 bilayer films' thickness were measured with a ZUS-4 micrometer (Yue Ming Small Machine Co., Changchun, China). The thickness measurements were taken at 10 random positions on each film, and the mean was calculated. The mean value for the thickness was used in calculating the film oxygen permeability (OP) and mechanical properties. The morphologies of the films were examined using SEM (FEI Quanta 200, Eindhoven, The Netherlands) equipped with a field-emission gun and Robinson detector, after the samples were vacuum-coated with thin layers of gold to minimize the charging effect. Attenuated total reflectance-Fourier transform infrared (ATR-FTIR) spectrometry (ATR-FTIR, Nicolet 5700, Thermo Nicolet Instrument Corp., Madison, WI, USA) was used to identify the chemical structures of the PVA/CH composite films and the possible interactions between their components. A small section cut from each composite film was used. The samples were analyzed with a resolution of $4 \mathrm{~cm}^{-1}$, an aperture setting of $6 \mathrm{~mm}$, a scanner velocity of $2.2 \mathrm{kHz}$, a background scan time of $32 \mathrm{~s}$, a sample scan time of $32 \mathrm{~s}$, and a total of 100 scans per sample, in the range of 400 to $4000 \mathrm{~cm}^{-1}$. The composite films were cut into rectangles of $50 \mathrm{~mm}$ in length and $5 \mathrm{~mm}$ in width for PVA/CH fibers. Tensile testing was performed using a universal testing machine (UTM, Instron 5583, Norwood, MA, USA) with the crosshead speed of $5 \mathrm{~mm} / \mathrm{min}$ and a $30 \mathrm{~mm}$ gauge length. The average value from five measured samples is reported for subsequent analysis.

\subsection{Strawberries Preparation and Packaging}

The strawberries were randomly divided into four groups and conducted with three replicates, with 10 strawberries in each treatment. The weight ratio of PVA:CH of 80:20, 75:25, and 70:30 were 
denoted as PVA/CH-2, PVA/CH-2.5, and PVA/CH-3, respectively. Ten strawberries (250 $\pm 10 \mathrm{~g})$ were packed in sealed PVA or PVA $/ \mathrm{CH}$ bags $(18 \mathrm{~cm} \times 18 \mathrm{~cm})$. These samples were placed in conditions of $18 \pm 2{ }^{\circ} \mathrm{C}$ and $60 \pm 5 \% \mathrm{RH}$. The quality of both packaged and control strawberries were evaluated after one day, two days, three days, four days, five days, and six days of storage.

\subsection{Oxygen and Water Vapor Permeability}

Permeability tests were performed using a PERME TM OX2/231 Permeability Tester from Labthink Instruments Co., Ltd. (Jinan, China), using oxygen as the test gas (RH 50\%) at a temperature of $18 \pm 2{ }^{\circ} \mathrm{C}$. Nitrogen was used as the oxygen carrier. The oxygen flow rate was fixed at $20 \mathrm{~mL} / \mathrm{min}$, while that of nitrogen was $10 \mathrm{~mL} / \mathrm{min}$. The WVPs of the films were determined by a Perme VAC-V1 (Labthink, Jinan, China) at $18 \pm 2{ }^{\circ} \mathrm{C}$ and $60 \% \mathrm{RH}$.

\subsection{Strawberry Quality during Storage}

\subsubsection{Total Soluble Solids (TSS) and pH Measurement}

Each group of strawberries was collected. Juice was obtained by homogenizing strawberries in a blender, and then filtering through a cheese cloth. The $\mathrm{pH}$ values of samples were determined with a pH meter (Sartorius PP-50, Goettingen, Germany) [47]. The TSS was determined using a digital refractometer (Atago, Tokyo, Japan).

\subsubsection{The Weight Loss}

Strawberry weight loss was measured using a balance $( \pm 0.0001 \mathrm{~g})$ and expressed according to the following formula:

$$
\text { Weight loss rate }(\%)=\left(W_{0}-W_{\mathrm{T}}\right) / W_{0} \times 100 \%
$$

where $W_{0}$ : the weight of the fresh strawberries, $W_{\mathrm{T}}$ : the weight of the strawberries after storage for specific time intervals.

\subsubsection{Microbiological Analyses and Decay Percentage}

The microbiological analyses were performed by the official standard method [44]. Mold and yeast counts were expressed as logarithm colony-forming units per gram of strawberries $(\log \mathrm{CFU} / \mathrm{g})$. Decay of the strawberries was recorded during each day of the experiment. Visible gray mold infections and wounded areas were photographed using a camera (Canon PowerShot S2IS, Canon Inc., Tokyo, Japan), and the images were processed using Adobe Photoshop CS 5.1 (Adobe Systems Inc., San Jose, CA, USA). The infected/wounded areas of each individual fruit were expressed as a decay percentage, and the mean wounded area content was calculated at each $\mathrm{CH}$ concentration level. The experiments were performed with five replications.

\subsubsection{Firmness}

The firmness of non-packaged and film-packaged strawberries was measured at $18 \pm 2{ }^{\circ} \mathrm{C}$ using a texture analyzer with a $5 \mathrm{~kg}$ load cell. A single, whole strawberry was placed on a floating platform and a $2 \mathrm{~mm}$ diameter flat head stainless steel cylindrical probe was set to penetrate $6 \mathrm{~mm}$ into the fruit at $1 \mathrm{~mm} / \mathrm{s}$ [43]. After the firmness measurements, the strawberries were cut into small pieces and homogenized for $2 \mathrm{~min}$ at high speed using a hand-held blender. The homogenized strawberry puree was divided into three groups of $5 \mathrm{~g}, 5 \mathrm{~g}$, and $10 \mathrm{~g}$.

\subsubsection{Titratable Acidity (TA)}

For the TA analyses, $5 \mathrm{~g}$ of the homogenized strawberry puree was put into $50 \mathrm{~mL}$ volumetric flask with the distilled water constant volume for $30 \mathrm{~min}$ and then filtered. Taking $20 \mathrm{~mL}$ filtrate 
titrated using $0.01 \mathrm{~mol} / \mathrm{L} \mathrm{NaOH}$. The total titratable acidity of the diluted puree was calculated using the formula:

$$
\mathrm{TA}=\left(V(\mathrm{NaOH}) \times 0.1 \times 0.064 \times V_{0}\right) /\left(m \times V_{1}\right)
$$

$V(\mathrm{NaOH})$ is the $\mathrm{mL}$ of $\mathrm{NaOH}$ spent for titration, 0.1 is the molarity of $\mathrm{NaOH}$ solution, 0.064 is conversion factor for citric acid; $V_{0}$ is the volumetric of the volumetric flask; $\mathrm{m}$ is filtrate volume. The results were expressed as percent citric acid (g citric acid/100 g dry weight). For determining soluble solids content (SSC), $5 \mathrm{~g}$ of homogenized strawberry puree was suspended in $10 \mathrm{~mL}$ distilled water and then filtered by filter paper.

\subsubsection{Ascorbic Acid Determination}

$10 \mathrm{~g}$ of the homogenized strawberry puree was suspended in a $50 \mathrm{~mL}$ volumetric flask with $10 \mathrm{~mL}$ of $1 \% \mathrm{HCl}$ and distilled water. The sample was then extracted at $1200 \mathrm{rad} / \mathrm{min}$ and centrifuged for $10 \mathrm{~min}$. The clean supernatant was collected and $1 \mathrm{~mL}$ put in each of two $50 \mathrm{~mL}$ volumetric flasks: (A) containing $2 \mathrm{~mL}$ of $10 \% \mathrm{HCl}$ and (B) containing $4 \mathrm{~mL}$ of $1 \mathrm{~mol} / \mathrm{L} \mathrm{NaOH}$, both with distilled water. Absorption photometry of the sample was conducted against a control at $243.3 \mathrm{~nm}$ using an absorption spectrophotometer (MAPADA, Instruments. Co., Ltd., Shanghai, China). The levels of ascorbic acid were estimated from a standard curve prepared from pure ascorbic acid readings.

\subsubsection{Preliminary Sensory Evaluation}

Strawberries from each set of treatment conditions were served to panelists in a random order. The evaluations were performed under ambient conditions at about $18 \pm 2{ }^{\circ} \mathrm{C}$ and $60 \% \pm 5 \% \mathrm{RH}$ in a sensory evaluation room. The quality attributes (appearance, color, odor, flavor, texture, and overall acceptability) of the strawberries were evaluated by 14 trained assessors, using a nine-point hedonic scale where 9 indicates excellence and freshness; 7 is very good; 5 is good but indicates the limit of marketability; 3 is fair, indicating the limit of usability; and 1 means poor or unusable. Panelists used water to cleanse their mouths between samples [44].

\subsection{Statistical Analysis}

Multiple samples were tested, and the results were reported as the mean \pm the standard deviation. The values were submitted to analysis of variance and the means were separated by Duncan's Multiple Range Test (SuperANOVA, Abacus Concepts, Inc., Berkeley, CA, USA). A $p$ value of $<0.05$ was considered significant.

\section{Conclusions}

PVA/CH blends exhibit better morphological and mechanical properties than neat PVA. They slow metabolic processes and delay strawberry ripening, as indicated by reductions in weight loss as well as retention of firmness, decay percentage, TA, TSS, and ascorbic acid content. PVA/CH bilayer films showed a beneficial effect on the maintenance of strawberry quality and freshness throughout the storage period. The PVA/CH-2.5 bilayer film balances the benefits of PVA and $\mathrm{CH}$ and may be the best choice for improving the quality and shelf lives of fresh strawberries for up to six days at $18 \pm 2{ }^{\circ} \mathrm{C}$ and a relative humidity of $60 \% \pm 5 \%$, with acceptable overall sensory scores.

Acknowledgments: We acknowledge the Natural Science Fund of Education Department of Sichuan province (16ZB0044 and 035Z1373).

Author Contributions: Yaowen Liu and Shuyao Wang developed the original idea and the protocol, abstracted and analyzed data, wrote the manuscript, and is guarantor. Wenting Lan and Wen Qin contributed to the development of the protocol, abstracted data, and prepared the manuscript.

Conflicts of Interest: The authors declare no conflict of interest. 


\section{References}

1. Van, D.V.F.; Tarola, A.M.; üemes, D.G.; Pirovani, M.E. Bioactive compounds and antioxidant capacity of Camarosa and Selva Strawberries (Fragaria $\times$ ananassa Duch). Food 2013, 2, 120-131.

2. Atress, A.S.H.; EI-Mogy, M.M.; Aboul-Anean, H.E.; Alsanius, B.W. Improving strawberries fruit storability by edible coating as carrier of thymol or calcium chloride. J. Hortic. Sci. Ornam. Plant. 2010, 2, 88-97.

3. Juliana, A.; Maria, R.; Rafael, A.; Jerri, G.; Annemiek, S.; Adam, L.G. Evaluation of chlorine dioxide as an antimicrobial against Botrytis cinerea in California strawberries. Food Packag. Shelf Life 2016, 9, 45-54.

4. Feliziani, E.; Landi, L.; Romanazzi, G. Preharvest treatments with chitosan and other alternatives to conventional fungicides to control postharvest decay of strawberry. Carbohydr. Polym. 2015, 132, 111-117. [CrossRef] [PubMed]

5. Harder, F.R.; Elgar, H.J.; Watkins, C.B.; Jackson, P.J.; Hallett, I.C. Physical and mechanical changes in strawberry fruit after high carbon dioxide treatments. Postharvest Biol. Technol. 2000, 19, 139-146.

6. Li, C.; Kader, A.A. Residual effects of controlled atmospheres on postharvest physiology and quality of strawberries. J. Am. Soc. 1989, 114, 629-634.

7. Krochta, J.M.; Elizabeth, A.B.; Myrna, O. Edible Coatings and Films to Improve Food Quality; Technomic Publishing Co.: Lancaster, PA, USA; pp. 201-277.

8. Lozano-Navarro, J.I.; Díaz-Zavala, N.P.; Velasco-Santos, C.; Martínez-Hernández, A.L.; Tijerina-Ramos, B.I.; García-Hernández, M.; Rivera-Armenta, J.L.; Páramo-García, U.; Reyes-de la Torre, A.I. Antimicrobial, optical and mechanical properties of chitosan-starch films with natural extracts. Int. J. Mol. Sci. 2017, 18, 997. [CrossRef] [PubMed]

9. Romanazzi, G.; Nigro, F.; Ippolito, A. Effectiveness of pre and postharvest chitosan treatments on storage decay of strawberries. Riv. Di Fruttic. e di Ortofloric. 2000, 62, 71-75.

10. Khalifa, I.; Barakat, H.; EI-Mansy, H.A.; Soliman, S.A. Improving the shelf-life stability of apple and strawberry fruits applying chitosan-incorporated olive oil processing residues coating. Food Packag. Shelf Life 2016, 9, 10-19. [CrossRef]

11. Velickova, E.; Winkelhausen, A.; Kuzmanova, S.; Alves, V.; Moldão-Martins, M. Impact of chitosan-beeswax edible coatings on the quality of fresh strawberries (Fragaria ananassa cv Camarosa) under commercial Storage Conditions. LWT-Food Sci. Technol. 2013, 62, 80-92. [CrossRef]

12. Hu, D.; Wang, L. Fabrication of antibouterial blend film from poly(vinyl alcohol)and quaternized chitosan for packaging. Mater. Res. Bull. 2016, 78, 46-52. [CrossRef]

13. Hyder, M.N.; Chen, P. Pervaporation dehydration of ethylene glycol with chitosan-poly(vinyl alcohol) blend membranes: Effect of CS-PVA blending ratios. J. Membr. Sci. 2009, 340, 171-180. [CrossRef]

14. Abdelrazek, E.M.; Elashmawi, I.S.; Labeeb, S. Chitosan filler effects on the experimental characterization, spectroscopic investigation and thermal studies of PVA/PVP blend films. Phys. B Condens. Matter 2010, 405, 2021-2027. [CrossRef]

15. Tripathi, S.; Mehrotra, G.K.; Dutta, P.K. Physicochemical and bioactivity of cross-linked chitosan-PVA film for food packaging applications. Int. J. Biol. Macromol. 2009, 45, 372-376. [CrossRef] [PubMed]

16. Batista, K.A.; Lopes, F.M.; Yamashita, F.; Fernandes, K.F. Lipase entrapment in PVA/Chitosan biodegradable film for reactor coatings. Mater. Sci. Eng. C Mater. 2013, 33, 1696-1701. [CrossRef] [PubMed]

17. Li, X.; Goh, S.H.; Lai, Y.H.; Wee, A.T.S. Miscibility of carboxyl-containing polysiloxane/poly(vinylpyridine) blends. Polymer 2000, 41, 6563-6571. [CrossRef]

18. Abdelaziz, M.; Abdelrazek, E.M. Effect of dopant mixture on structural, optical and electron spin resonance properties of polyvinyl alcohol. Phys. B Condensed Matter 2007, 390, 1-9. [CrossRef]

19. Cao, S.; Shi, Y.; Chen, G. Blend of chitosan acetate salt with poly(n-vinyl-2-pyrrolidone): Interaction between chain-chain. Mater. Res. Bull. 1998, 41, 553-559. [CrossRef]

20. Farris, S.; Introzzi, L.; Biagioni, P.; Holz, T.; Schiraldi, A.; Piergiovanni, L. Wetting of biopolymer coatings: Contact angle kinetics and image analysis investigation. Langmuir 2011, 27, 7563-7574. [CrossRef] [PubMed]

21. Kim, J.H.; Kim, J.Y.; Lee, Y.M.; Kim, K.Y. Properties and swelling characteristics of cross-linked poly(vinyl alcohol) chitosan blend membrane. J. Appl. Polym. Sci. 1992, 45, 1711-1717. [CrossRef]

22. Mispo, V.M.; Mansur, A.A.; Barbosa-Stancioli, E.F.; Mansur, H.S. Biocompatibility of nanostructured chitosan/poly(vinyl alcohol) blends chemically crosslinked with genipin for biomedical applications. J. Biomed. Nanotechnol. 2010, 6, 166-175. 
23. Quirozcastillo, J.M.; Rodríguezfélix, D.E.; Grijalvamonteverde, H.; Del, C.T.; Plascenciajatomea, M.; Rodríguezfélix, F.; Pedro, H.F. Preparation of extruded polyethylene/chitosan blends compatibilized with polyethylene-graft-maleic anhydride. Carbohydr. Polym. 2014, 101, 1094-1100. [CrossRef] [PubMed]

24. Pelissari, F.M.; Yamashita, F.; Mve, G. Extrusion parameters related to starch/chitosan active films properties. Int. J. Food Sci. Technol. 2011, 46, 702-710. [CrossRef]

25. Hang, A.T.; Tae, B.; Park, J.S. Non-woven mats of poly(vinyl alcohol)/chitosan blends containing silver nanoparticles: Fabrication and characterization. Carbohydr. Polym. 2010, 82, 472-479. [CrossRef]

26. Laxmeshwar, S.S.; Viveka, S.; Madhu Kumar, D.J.; Dinesha; Bhajanthri, R.F.; Nagaraja, G.K. Preparation and characterization of modified cellulose fiber-reinforced polyvinyl alcohol/polypyrrolidone hybrid film composites. Macromol. Sci. A 2012, 49, 639-647. [CrossRef]

27. Fernandezsaiz, P.; Soler, C.; Lagaron, J.M.; Ocio, M.J. Effects of chitosan films on the growth of Listeria monocytogenes, Staphylococcus aureus and Salmonella spp. in laboratory media and in fish soup. Int. J. Food Microbiol. 2010, 137, 287-294. [CrossRef] [PubMed]

28. Kanatt, S.R.; Rao, M.S.; Chawla, S.P.; Sharma, A. Active chitosan-polyvinyl alcohol films with natural extracts. Food Hydrocoll. 2012, 29, 290-297. [CrossRef]

29. Han, C.; Zhao, Y.; Leonard, S.W.; Traber, M.G. Edible coatings to improve storability and enhance nutritional value of fresh and frozen strawberries (Fragaria $\times$ ananassa) and raspberries (Rubus ideaus). Postharvest Biol. Technol. 2004, 33, 67-78. [CrossRef]

30. Martinez-Ferrer, M.; Harper, C.; Perez-Muroz, F.; Chaparro, M. Modified atmosphere packaging of minimally processed mango and pineapple fruits. J. Food Sci. 2002, 67, 3365-3371. [CrossRef]

31. Cong, F.S.; Zhang, Y.G.; Dong, W.Y. Use of surface coatings with natamycin to improve the storability of Hami melon at ambient temperature. Postharvest Biol. Technol. 2007, 46, 71-75. [CrossRef]

32. Almenar, E.; Del-Valle, V.; Hernández-Muñoz, P.; Lagarón, J.M.; Catalá, R.; Gavara, R. Equilibrium modified atmosphere packaging of wild strawberries. J. Sci. Food Agric. 2007, 87, 1931-1939. [CrossRef]

33. Duan, J.; Wu, R.; Strik, B.C.; Zhao, Y. Effect of edible coatings on the quality of fresh blueberries (Duke and Elliott) under commercial storage conditions. Postharvest Biol. Technol. 2011, 59, 71-79. [CrossRef]

34. Maqbool, M.; Ali, A.; Alderson, P.G.; Zahid, N.; Siddiqui, Y. Effect of a novel edible composite coating based on gum arabic and chitosan on biochemical and physiological responses of banana fruits during cold storage. J. Agric. Food Chem. 2011, 59, 5474-5482. [CrossRef] [PubMed]

35. Abugoch, L.E.; Tapia, C.; Villamán, M.C.; Yazdanipedram, M.; Díazdosque, M. Characterization of quinoa protein-chitosan blend edible films. Food Hydrocoll. 2011, 25, 879-886. [CrossRef]

36. Bai, R.K.; Huang, M.Y.; Jiang, Y.Y. Selective permeabilities of chitosan-acetic acid complex membrane and chitosan-polymer complex membranes for oxygen and carbon dioxide. Polym. Bull. 1998, 20, 83-88. [CrossRef]

37. Perkins-Veazie, P. Growth and ripening of strawberry fruit. Hortic. Rev. 2010, 17, 267-297.

38. Harker, F.R.; Redgwell, R.J.; Hallett, I.C.; Murray, S.H.; Carter, G. Texture of fresh fruit. Hortic. Rev. 1997, 8, 13-18.

39. Velickova, E.; Winkelhausen, E.; Kuzmanova, S.; Moldão-Martins, M.; Alves, V.D. Characterization of multilayered and composite edible films from chitosan and beeswax. Characterization of multilayered and composite edible films from chitosan and beeswax. LWT Food Sci. Technol. 2015, 21, 83-93.

40. Villarreal, N.M.; Rosli, H.G.; Martínez, G.A.; Civello, P.M. Polygalacturonase activity and expression of related genes during ripening of strawberry cultivars with contrasting fruit firmness. Postharvest Biol. Technol. 2008, 47, 141-150. [CrossRef]

41. Hernández-Muñoz, P.; Almenar, E.; Ocio, M.J.; Gavara, R. Effect of calcium dips and chitosan coatings on postharvest life of strawberries (fragaria $\times$ ananassa). Postharvest Biol. Technol. 2006, 39, 247-253. [CrossRef]

42. Gol, N.B.; Patel, P.R.; Rao, T.V.R. Improvement of quality and shelf-life of strawberries with edible coatings enriched with chitosan. Postharvest Biol. Technol. 2013, 85, 185-195. [CrossRef]

43. Sangsuwan, J.; Pongsapakworawat, T.; Bangmo, P.; Sutthasupa, S. Effect of chitosan beads incorporated with lavender or red thyme essential oils in inhibiting botrytis cinerea and their application in strawberry packaging system. LWT-Food Sci. Technol. 2016, 74, 14-20. [CrossRef]

44. Valenzuela, C.; Tapia, C.; López, L.; Escalona, V.; Abugoch, L. Effect of edible quinoa protein-chitosan based films on refrigerated strawberry (Fragaria $\times$ ananassa) quality. Electron. J. Biotechnol. 2015, 6, 406-411. [CrossRef] 
45. El Ghaouth, A.; Arul, J.; Asselin, A.; Benhamou, N. Antifungal activity of chitosan on post-harvest pathogens: Induction of morphological and cytological alterations in Rhizopus stolonifer. Mycol. Res. 1992, 96, 769-779. [CrossRef]

46. Bautista-Baños, S.; An, H.L.; Velázquez Del Valle, M.G.; Hernández-López, M.; Ait Barka, E.; Bosquez-Molina, E.; Bosquez-Molina, E.; Wilson, C.L. Chitosan as a potential natural compound to control pre and postharvest diseases of horticultural commodities. Crop. Prot. 2006, 25, 108-118. [CrossRef]

47. Aday, M.S.; Caner, C. The applications of active packaging and chlorine dioxide for extended shelf life of fresh strawberries. Packag. Technol. Sci. 2011, 24, 123-136. [CrossRef]

(C) 2017 by the authors. Licensee MDPI, Basel, Switzerland. This article is an open access article distributed under the terms and conditions of the Creative Commons Attribution (CC BY) license (http:/ / creativecommons.org/licenses/by/4.0/). 